\title{
A practical approach to scale-adaptive deep convection in a GCM by controlling the cumulus base mass flux
}

\author{
Min-Seop Ahn ${ }^{1,2,3}$ and In-Sik Kang ${ }^{3,4}$
}

As the horizontal resolution of general circulation model (GCM) is increased, the sub-grid scale vertical transport has to be decreased appropriately. In the present study, a resolution-dependent (so-called scale-adaptive or scale-aware) deep convection was formulated by controlling the cumulus base mass flux. Using a three-dimensional cloud resolving model simulation, we estimated the appropriate ratios of the sub-grid scale vertical transport to the total vertical transport of moist static energy for different horizontal resolutions, whose values are about 0.8 for $100 \mathrm{~km}$ resolution and about 0.6 for $50 \mathrm{~km}$ resolution. Those values were used as a guideline to decrease to the ratio of convective precipitation to the total precipitation in a high-resolution GCM. The cumulus base mass flux is reduced by multiplying a reduction coefficient, which is 0.2 for the $100 \mathrm{~km}$ resolution and 0.09 for the $50 \mathrm{~km}$ resolution in the present GCM. The GCM with the scale-adaptive deep convection produces the climatological mean precipitation similar to that of the original GCM, whereas it simulates the heavy precipitation frequency and the Madden and Julian Oscillation much better than those of the original GCM.

npj Climate and Atmospheric Science (2018)1:13; doi:10.1038/s41612-018-0021-0

\section{INTRODUCTION}

Conventional general circulation models (GCMs) have two processes to produce total precipitation. One is the grid scale precipitation formulated by a large-scale condensation scheme (or stratiform cloud scheme), and the other is the sub-grid scale precipitation formulated by a convection scheme. The main role of the convection scheme is parameterization of unresolved sub-grid scale vertical transport in coarse horizontal resolution GCMs, accompanying the convective condensation and precipitation process. The horizontal resolutions of GCMs have been increasing due to the development of computing power, and the highresolution GCMs have the capability to simulate more resolved grid scale vertical transport. As the horizontal resolution of GCMs becomes higher than the order of $10 \mathrm{~km}$, convections can be partly resolved by grid scale vertical transport. ${ }^{1}$ Therefore, GCMs with the order of $10 \mathrm{~km}$ horizontal resolution have the problem of how to represent the convection, which is so-called the Grey Zone problem. $^{2}$

Many convection schemes have been developed based on several different concepts. The detailed review of the different types of convection scheme is described in Arakawa. ${ }^{3}$ Among the different types of convection schemes, the mass flux type convection schemes have been developed by many modeling groups. ${ }^{4-11}$ To overcome the Grey Zone problem, Arakawa and $\mathrm{Wu}^{12}$ presented a resolution-dependent (so-called scale-adaptive or scale-aware) deep convection scheme based on a mass flux type convection scheme, which is formulated to reduce the subgrid scale vertical transport as the horizontal resolution increases. They controlled the cumulus base mass flux as a function of the convective cloud fraction to reduce the sub-grid scale vertical transport. Kwon and Hong ${ }^{13}$ also presented a scale-adaptive deep convection scheme based on the convective cloud fraction like
Arakawa and $\mathrm{Wu}^{12}$ but they used another additional variable of a function of the grid scale and convective vertical velocity to control the cumulus base mass flux. Kwon and Hong ${ }^{13}$ showed that the scale-adaptive deep convection scheme by controlling the cloud base mass flux, convective inhibition, and convective detrainment simulates well the 24-h accumulated rainfall of a heavy rainfall case over Korea in the Weather Research and Forecasting (WRF) model simulation. For these ways, however, the additional parameterization of the convective cloud fraction is required. In this study, we present a practical approach for a scaleadaptive convection scheme by directly controlling the cumulus base mass flux without additional parameterizations based on the ratio of sub-grid scale vertical transport to total vertical transport obtained from Cloud Resolving Model (CRM) simulation. On the other hand, the necessity of formulating the scale-adaptive convection is debatable. ${ }^{14,15}$ To understand the necessity of the scale-adaptive convection in more practical terms, it is required to examine the inherent change of the sub-grid scale vertical transport formulated by the convection scheme as the horizontal resolution increases in GCMs.

This study focused on three objectives: (1) Examining the inherent change of the sub-grid scale vertical transport as the horizontal resolution increases using a GCM with different horizontal resolution simulations. (2) Finding the appropriate ratio of the sub-grid scale vertical transport to the total vertical transport as the horizontal resolution increases using a threedimensional CRM simulation. (3) Formulating the scale-adaptive deep convection in the GCM by controlling the cumulus base mass flux based on the ratios obtained from the CRM simulation. The rest of this paper is organized as follows. The horizontal resolution dependency in a GCM, ratio of the sub-grid scale vertical transport to the total vertical transport as a function of the

\footnotetext{
${ }^{1}$ Department of Oceanography, Chonnam National University, Gwangju, Korea; ${ }^{2}$ Department of Atmospheric Sciences, University of Washington, Seattle, WA, USA; ${ }^{3}$ School of Earth and Environmental Sciences, Seoul National University, Seoul, Korea and ${ }^{4}$ Center of Excellence of Climate Change Research, King Abdulaziz University, Jeddah, Saudi Arabia Correspondence: I-S. Kang (insik.kang1@gmail.com)
}

Received: 29 June 2017 Revised: 18 January 2018 Accepted: 30 January 2018

Published online: 11 June 2018 
horizontal resolution in a CRM, and the GCM with the scaleadaptive deep convection scheme are described below. A summary and discussions are given in the section Summary and discussion.

\section{RESULTS}

Horizontal resolution dependency in a GCM

The GCM used in this study is the Seoul National University Atmospheric General Circulation Model (SNUAGCM). The model and experimental design are described in the Methods section. As shown in Fig. 1, the spatial patterns of the precipitation mean state from the GCM with different horizontal resolutions are similar to each other, but the intensities of the precipitation mean state are slightly increased and positively biased from the observation in the South Pacific Convergence Zone (SPCZ) and the Intertropical Convergence Zone (ITCZ) regions as the horizontal resolution increases. The ratio of the convective precipitation generated by the deep convection scheme to the total precipitation is not much changed as the horizontal resolution increases over the Tropics. This result implies that the increased total precipitation in SPCZ region as increasing the horizontal resolution is due to not only the increased grid scale precipitation but also the increased sub-grid scale convective precipitation generated by the deep convection scheme.
The amount of the grid scale precipitation and the sub-grid scale convective precipitation are proportional to the intensity of $\omega$ and cumulus mass flux, respectively. Figure 2 shows the vertical profiles of the $\omega$ and cumulus mass flux composite from the GCM with different horizontal resolutions. The composite is carried out over the Tropics $\left(0^{\circ} \mathrm{E}-360^{\circ} \mathrm{E}, 30^{\circ} \mathrm{S}-30^{\circ} \mathrm{N}\right)$ using the grids in which precipitation and upward vertical motion occur (precipitation $>0$ and $\omega 850<0$ ). Present study focused on controlling the cumulus base mass flux. Therefore, we focused on analyzing and showing in the change of updraft column. Both of the $\omega$ and cumulus mass flux are increased at all vertical levels (solid curves) as the horizontal resolution increases, which can induce the increase of the total precipitation intensity. To decrease the overestimated precipitation in higher resolution simulations, the cumulus mass flux should be decreased to reduce the convective precipitation generated by the deep convection scheme. The appropriate decrease ratio of the cumulus mass flux is examined with a threedimensional CRM simulation in the section Ratio of sub-grid scale vertical transport to total vertical transport in CRM.

Ratio of sub-grid scale vertical transport to total vertical transport in CRM

The moist static energy (h) equation is useful to examine simulated vertical transport because the moist static energy is a nearly conserved physical quantity for condensation. After grid averaging, the vertical transport term of the moist static energy

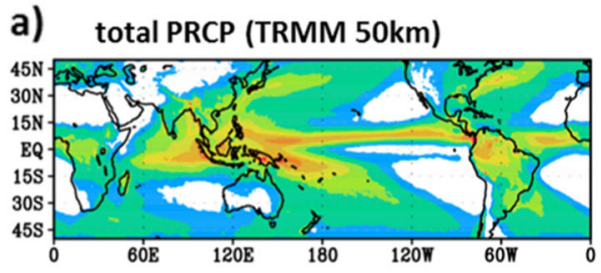

b) total PRCP (AGCM $280 \mathrm{~km})$

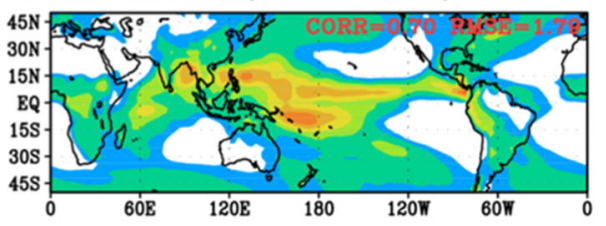

d) total PRCP (AGCM $100 \mathrm{~km})$

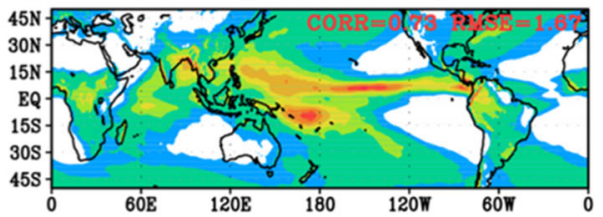

f) total PRCP (AGCM 50km)

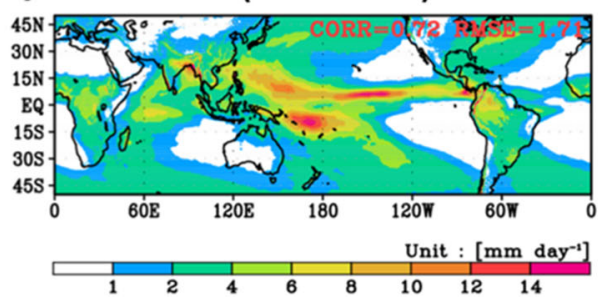

c) convective PRCP ratio (AGCM $280 \mathrm{~km}$ )

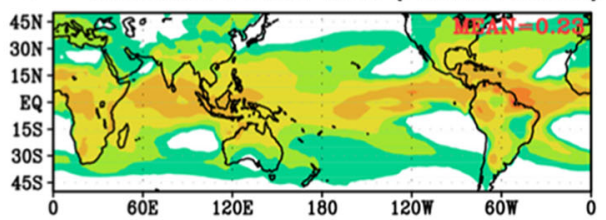

e) convective PRCP ratio (AGCM 100km)

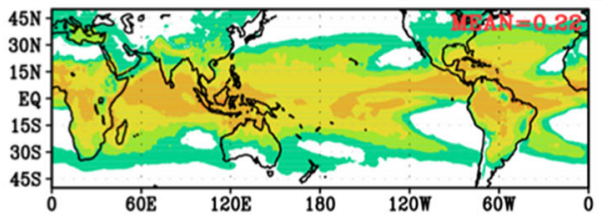

g) convective PRCP ratio (AGCM 50km)

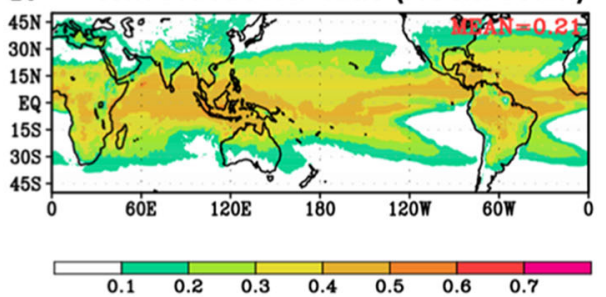

Fig. 1 Total precipitation mean state for a TRMM, b GCM with $280 \mathrm{~km}$ resolution, d GCM with $100 \mathrm{~km}$ resolution, and $\mathbf{f}$ GCM with $50 \mathrm{~km}$ resolution. Ratio of the convective precipitation generated by the deep convection scheme to the total precipitation for $\mathrm{c}$ GCM with $280 \mathrm{~km}$ resolution, e GCM with $100 \mathrm{~km}$ resolution, and $\mathbf{g}$ GCM with $50 \mathrm{~km}$ resolution. TRMM was interpolated to the $50 \mathrm{~km}$ resolution. The spatial correlation and RMSE are calculated with GCM and the TRMM interpolated to GCM's resolution. The spatial correlation, RMSE, and area mean are calculated over whole domain of the figures $\left(0-360^{\circ} \mathrm{E}\right.$ and $\left.50^{\circ} \mathrm{S}-50^{\circ} \mathrm{N}\right)$ 

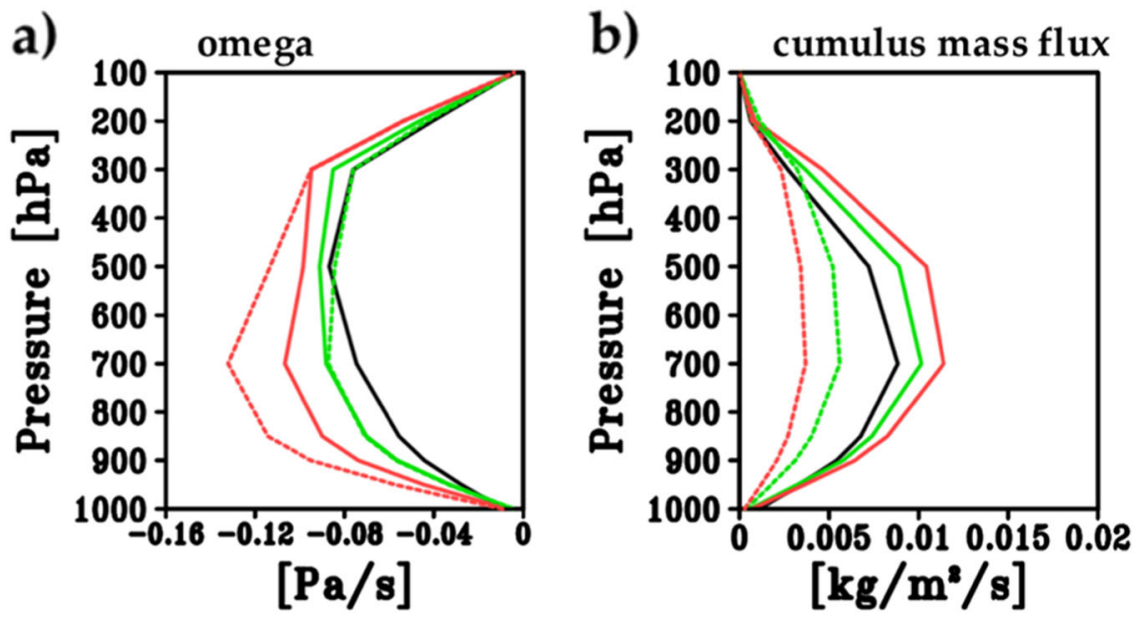

$\begin{aligned}-280 \mathrm{~km} \text { org } & -100 \mathrm{~km} \text { org } \quad-50 \mathrm{~km} \text { org } \\ & --100 \mathrm{~km} \text { s.a.DC }--50 \mathrm{~km} \mathrm{s.a.DC}\end{aligned}$

Fig. 2 Vertical profiles of the $\mathbf{a} \omega$ and $\mathbf{b}$ cumulus mass flux composite from the GCM with original convection (solid curves) and the GCM with the scale-adaptive convection (dashed curves) for the $100 \mathrm{~km}$ (green) and $50 \mathrm{~km}$ (red) resolutions, and the GCM with original convection for the $280 \mathrm{~km}$ resolution (black). The composite was carried out over the Tropics $\left(0^{\circ} \mathrm{E}-360^{\circ} \mathrm{E}, 30^{\circ} \mathrm{S}-30^{\circ} \mathrm{N}\right)$ using the grids in which precipitation and upward vertical motion occur (precipitation $>0$ and $\omega 850<0$ )

equation becomes the following:

$\overline{w \frac{\partial h}{\partial z}}=\bar{w} \frac{\partial \bar{h}}{\partial z}+\overline{w^{\prime} \frac{\partial h^{\prime}}{\partial z}}$

Here, $h=C_{p} T+g z+L q$ is the moist static energy, and $w$ is the vertical wind velocity. In the moist static energy, $T$ is the air temperature, $z$ is the geopotential height, $q$ is the specific humidity, $C_{P}$ is the specific heat at constant pressure $\left(1004 \mathrm{~J} \mathrm{~K}^{-1}\right.$ $\left.\mathrm{kg}^{-1}\right), g$ is the gravitational acceleration $\left(9.8 \mathrm{~m} \mathrm{~s}^{-2}\right)$, and $L$ is the latent heat of vaporization $\left(2.5 \times 10^{6} \mathrm{~J} \mathrm{~kg}^{-1}\right)$. The overbar and prime indicate the grid mean and the anomaly deviated from the grid mean, respectively. Note that we defined $w \frac{\partial h}{\partial z}$ as the total vertical transport term, $\bar{w} \frac{\partial \bar{h}}{\partial z}$ as the grid scale vertical transport term, and $w^{\prime} \frac{\partial h^{\prime}}{\partial z}$ as the sub-grid scale vertical transport term.

The CRM used in this study is the Goddard Cumulus Ensemble (GCE) model. The model description and experimental design are in the Methods section. Figures $3 a$ and $3 b$ shows the ratio of the area averaged vertical transport of moist static energy at $850 \mathrm{hPa}$ level for the grid scale vertical transport to the total vertical transport and the sub-grid scale vertical transport to the total vertical transport as a function of the averaged grid size in threedimensional CRM with $1 \mathrm{~km}$ horizontal resolution. The area averaged composite is conducted over only the updraft domains $\left(\overline{\mathrm{w}}>0\right.$ and $\left.\frac{\partial \bar{h}}{\partial z}<0\right)$. As the averaged grid size becomes larger, the fraction of the grid scale vertical transport is decreased and the fraction of the sub-grid scale vertical transport is increased, indicating that the role of sub-grid scale transport is small in higher resolution and large in lower resolution. Thus, this result implies that the conventional deep convection scheme in the GCM should reduce their role as the model resolution increases. The ratios of the sub-grid scale vertical transport to the total vertical transport obtained from the CRM simulation are about 0.8 for the $100 \mathrm{~km}$ resolution and about 0.62 for the $50 \mathrm{~km}$ resolution. These ratios were used as a guideline to appropriately decrease the sub-grid scale vertical transport of the GCM in the section GCM with the scale-adaptive deep convection scheme.

GCM with the scale-adaptive deep convection scheme

The ratio of the sub-grid scale vertical transport to the total vertical transport for the moist static energy in the GCM is obtained by the different method from the CRM's method because of the sub-grid scale variable availability. The grid scale vertical transport is directly calculated by the grid-mean state variables. But, the sub-grid scale vertical transport is estimated by the tendencies of the temperature and specific humidity parameterized by the convection scheme. The total vertical transport is obtained by the sum of the grid scale vertical transport and the sub-grid scale vertical transport.

To estimate the sub-grid scale vertical transport for the moist static energy in the GCM, the tendencies of the temperature and specific humidity parameterized by the deep convection and shallow convection scheme are used as follows:

$C_{P}\left(\frac{\partial T}{\partial \mathrm{t}}\right)_{\mathrm{DC}, \mathrm{SC}}+L\left(\frac{\partial q}{\partial t}\right)_{\mathrm{DC}, \mathrm{SC}} \approx\left(\frac{\partial \overline{\omega^{\prime} h^{\prime}}}{\partial p}\right)_{\mathrm{DC}, \mathrm{SC}}$

Here, $T, q$, and $\omega$ indicate the temperature, specific humidity, and pressure vertical velocity, respectively. $C_{P}$ and $L$ indicate the specific heat of dry air at constant pressure $\left(1004 \mathrm{~J} \mathrm{~K}^{-1} \mathrm{~kg}^{-1}\right)$ and the latent heat of condensation $\left(2.5 \times 10^{6} \mathrm{~J} \mathrm{~kg}^{-1}\right)$, respectively. DC and SC indicate the deep convection and shallow convection. The overbar and prime indicate the grid mean and the anomaly deviated from the grid mean. Note that the $\frac{\partial \bar{\omega}^{\prime} z^{\prime}}{\partial p}$ term is zero in the hydrostatic GCM.

Figure $3 \mathrm{C}$ shows the ratio of the domain averaged $\left(0^{\circ} \mathrm{E}-360^{\circ} \mathrm{E}\right.$, $30^{\circ} \mathrm{S}-30^{\circ} \mathrm{N}$ ) sub-grid scale vertical transport to the total vertical transport for the moist static energy at $850 \mathrm{hPa}$ level. Only the updraft domains $\left(\bar{\omega}<0\right.$ and $\left.\frac{\partial \bar{h}}{\partial p}>0\right)$ are used for the calculation in the GCM. The reason for using the $850 \mathrm{hPa}$ level is that the cumulus base level exists around the $850 \mathrm{hPa}$ level generally, and the cumulus base mass flux directly influences on the intensity of the mass flux over all levels. The ratios for the GCM are normalized by the ratio of $280 \mathrm{~km}$ simulation which is about 0.53 . The GCM with different horizontal resolution (blue bars) show not much change in the ratio as the horizontal resolution increases. The ratios in the GCM do not agree with the ratios obtained from the CRM simulation (red curve), which implies the necessity of the decrease in the sub-grid scale vertical transport.

The cumulus base mass flux is used as a control parameter to decrease the sub-grid scale vertical transport in the GCM. In the mass flux type convection scheme, the cumulus cloud equation set is normalized by the cumulus base mass flux, and the intensity is obtained by multiplying the cumulus base mass flux to the 

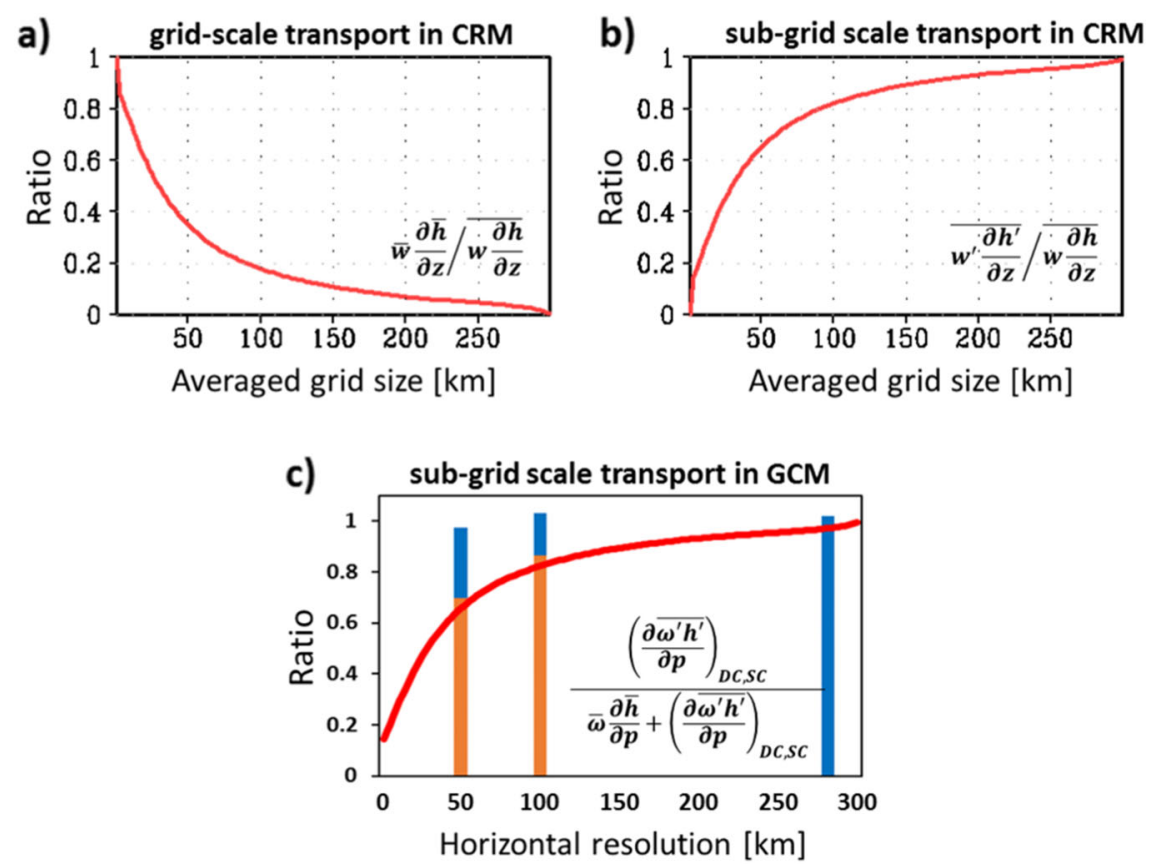

Fig. 3 Resolution dependency of the $850 \mathrm{hPa}$ moist static energy vertical transport for a the ratio of the grid scale vertical transport to the total vertical transport based on the averaged gird size in CRM, $\mathbf{b}$ the ratio of the sub-grid scale vertical transport to the total vertical transport based on the averaged gird size in CRM, and c the ratio of the sub-grid scale vertical transport to the total vertical transport in 50, 100, and $280 \mathrm{~km}$ CGMs. Blue bars indicate the original simulation, and orange bars indicate the scale-adaptive simulation. Red curve in the panel $\mathrm{c}$ is the same with that in the panel $\mathbf{b}$. In the CRM result, only the updraft domains $\left(\bar{w}>0\right.$ and $\left.\frac{\partial \bar{h}}{\partial z}<0\right)$ among all averaged domains were used to calculation. In the GCM result, only the updraft domains $\left(\bar{\omega}<0\right.$ and $\left.\frac{\partial \bar{h}}{\partial p}>0\right)$ among tropical domains $\left(0^{\circ} \mathrm{E}-360^{\circ} \mathrm{E}, 30^{\circ} \mathrm{S}-30^{\circ} \mathrm{N}\right)$ were used to calculation, and the ratio for the GCM was normalized by the $280 \mathrm{~km}$ simulation result

normalized solution. Therefore, the cumulus base mass flux controls the intensity of the convection and is considered as the closure in the convection scheme. ${ }^{4}$ Controlling the cumulus base mass flux is a similar framework with other scale-adaptive convection studies. ${ }^{12,13}$ Those studies control the cumulus base mass flux based on the theoretical derivation, while present study controls the cumulus base mass flux based on the practical method. The reduction coefficients, which are directly multiplied to the cumulus base mass flux to reduce the intensity of the cumulus base mass flux, are 0.2 and 0.09 for the 100 and $50 \mathrm{~km}$ simulations, respectively. These values were obtained from sensitivity tests to fit the ratio of the CRM simulation. The subgrid scale vertical transport was not linearly proportional to the reduction coefficient in the time-mean sense because the sub-grid scale vertical transport at each time step is influenced by not only the reduction coefficient but also by the instability of the atmosphere at each time step. The instability of the atmosphere at each time is increased because the stabilization effect of the deep convection is reduced by the multiplying reduction coefficient. In the Fig. $3 c$, the scale-adaptive GCM simulations with 100 and $50 \mathrm{~km}$ horizontal resolutions (orange bars) well fit in the ratios obtained from the CRM simulation (red curve).

To examine the basic property of the scale-adaptive GCM, the mean precipitation was diagnosed. Figure 4 shows the spatial pattern of the precipitation mean state from the 100 and $50 \mathrm{~km}$ GCM simulations with the scale-adaptive convection. The spatial patterns are similar to the original simulation, but the intensities are somewhat decreased over the SPCZ and ITCZ regions compared to the original GCM simulation (Fig. 1d, f). The ratio of the convective precipitation generated by the deep convection scheme to the total precipitation is decreased globally in the 100 and $50 \mathrm{~km} \mathrm{GCM}$ simulations with the scale-adaptive convection. These ratios only considered the convective precipitation formulated by the deep convection scheme. The convective precipitation can be also formulated by the resolved grid scale vertical transport with large-scale condensation to some extent in the high-resolution GCMs. Therefore, it is difficult to directly compare with the convective precipitation ratio obtained from the observation. Although the precipitation mean state is not much changed, the convective precipitation generated by the deep convection scheme is decreased. This result indicates that the resolved grid scale convective precipitation is increased to compensate for the decreased sub-grid scale convective precipitation. The resolved grid scale precipitation is influenced by the grid scale vertical velocity, and the parameterized sub-grid scale precipitation is influenced by the cumulus mass flux. Figure 2 showed the vertical profiles of the $\omega$ and cumulus mass flux composite from the GCM with the original convection (solid curves) and the scale-adaptive convection (dashed curves) for different horizontal resolutions. As the horizontal resolution increases, the $\omega$ is more increased, and the cumulus mass flux is decreased in the GCM with scale-adaptive convection compared to the GCM with original convection. This result indicates that the convective precipitation is formulated by the resolved grid scale vertical transport with large-scale condensation to some extent in the GCM with scale-adaptive convection, which is so-called convection-permitting model.

Although the precipitation mean state is not much changed, the precipitation variance is increased in the 100 and $50 \mathrm{~km} \mathrm{GCM}$ simulations with the scale-adaptive convection (not shown). This result indicates that the scale-adaptive convection can induce a more frequency of strong and weak precipitation. Many GCMs underestimate the strong precipitation frequency. ${ }^{16,17}$ Figure 5 shows the frequency distribution of the three-hourly mean precipitation based on the precipitation strength. The original GCM tends to simulate strong precipitation less and weak precipitation more. However, the GCM with the scale-adaptive 
a) total PRCP $(100 \mathrm{~km})$

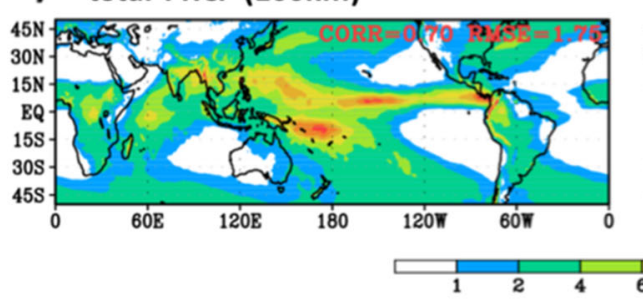

\section{b) total PRCP $(50 \mathrm{~km})$}

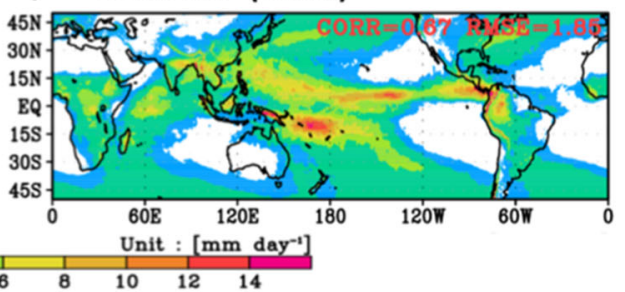

c) total PRCP diff from org $(100 \mathrm{~km})$

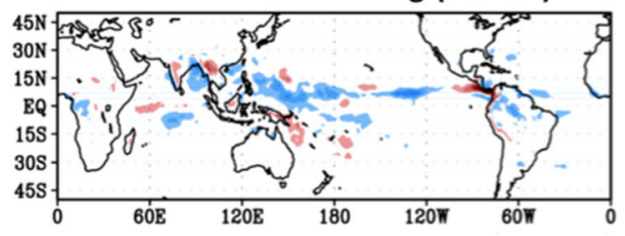

\section{d) total PRCP diff from org $(50 \mathrm{~km})$}

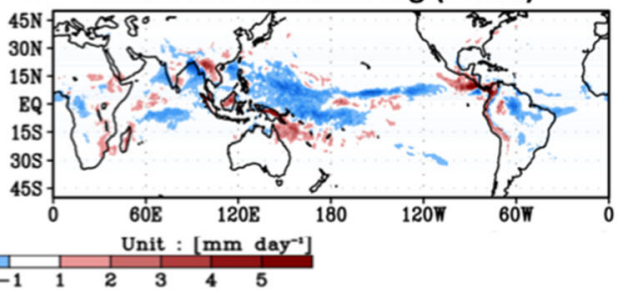

e) convective PRCP ratio $(100 \mathrm{~km})$

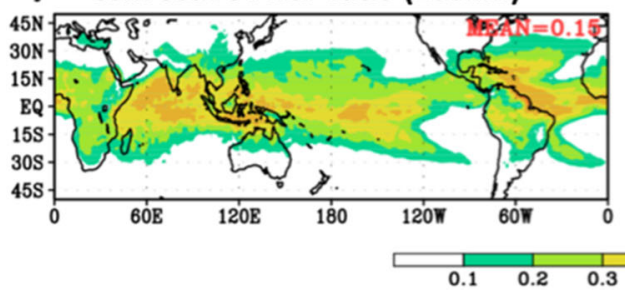

\section{f) convective PRCP ratio $(50 \mathrm{~km})$}

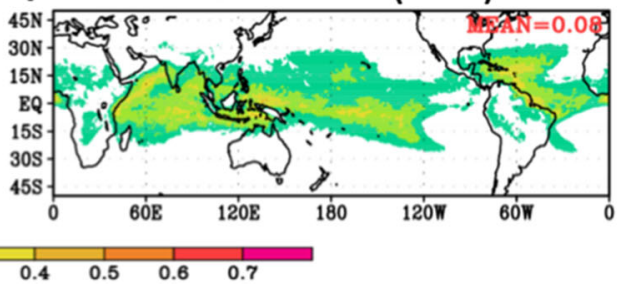

Fig. 4 Total precipitation mean state from the GCM with the scale-adaptive convection for the a 100 and $\mathbf{b} 50 \mathrm{~km}$ resolutions. Difference of total precipitation mean state from the GCM with original convection for the c 100 and d $50 \mathrm{~km}$ resolutions. Ratio of the convective precipitation generated by the deep convection scheme to the total precipitation from the GCM with the scale-adaptive convection for the e 100 and $\mathbf{f} 50 \mathrm{~km}$ resolutions. The spatial correlation and RMSE are calculated with GCM and the TRMM interpolated to GCM's resolution. The spatial correlation, RMSE, and area mean are calculated over whole domain of the figures $\left(0-360^{\circ} \mathrm{E}\right.$ and $\left.50^{\circ} \mathrm{S}-50^{\circ} \mathrm{N}\right)$

convection simulates the strong and weak precipitation reasonably well compared to the original GCM.

To examine the MJO simulation, the lag-longitude diagram of the $10^{\circ} \mathrm{S}-10^{\circ} \mathrm{N}$ averaged zonal wind at $850 \mathrm{hPa}$ based on the Indian Ocean was used (Fig. 6). In the observation, eastward propagations are clearly apparent, whereas the eastward propagations in the original GCMs are poorly simulated. Only increasing the horizontal resolution does not have much effect on improving the MJO simulation, which is consistent with previous results. ${ }^{18-21}$ However, increasing the horizontal resolution with the scaleadaptive convection simulates the eastward propagation reasonably well although the propagation speed is somewhat faster than that of the observation. It indicates that the MJO is well represented in the model with more resolved precipitation which induced by inhibiting the parameterized precipitation. Our result is consistent with the previous studies about that the triggering of the convection, such as a minimum entrainment rate constraint which is so-called Tokioka constraint, ${ }_{1}^{22}$ helps the well simulation of the MJO. ${ }^{23,24}$ In other words, the increase of resolved grid scale convective precipitation induces the decrease of the uncertainty originated from the convective parameterization, such as the steady-state assumption in convective parameterization which can induce too frequent precipitation.

\section{SUMMARY AND DISCUSSION}

The resolved grid scale vertical transport in a GCM increases as the horizontal resolution increases, and hence the parameterized subgrid scale vertical transport should be decreased. To understand the necessity of the scale-adaptive convection, the inherent change of the mean precipitation, the ratio of the convective precipitation generated by deep convection scheme to the total precipitation, and the ratio of the sub-grid scale vertical transport to the total vertical transport for the moist static energy was examined as the horizontal resolution was increased. The GCM with different horizontal resolutions showed that the simulated precipitation intensity was slightly overestimated in the SPCZ and $I T C Z$, and the ratio of the sub-grid scale vertical transport to the total vertical transport was not much changed as the horizontal resolution was increased. It implied the necessity of the appropriate decrease of sub-grid scale vertical transport as the horizontal resolution increases, which is so-called scale-adaptive convection. The appropriate ratio of the sub-grid scale vertical transport to the total vertical transport was estimated by the three-dimensional CRM simulation with $1 \mathrm{~km}$ horizontal resolution. The vertical transport term of the moist static energy equation after grid averaging was used to examine the appropriate ratio. The ratios of the sub-grid scale vertical transport to the total vertical transport obtained from the CRM simulation were about 0.8 and 0.62 for 100 and $50 \mathrm{~km}$ resolutions, respectively. Authors need to note that the large-scale circulations, such as Hadley and Walker circulation, are not included in this CRM simulation. If the large-scale circulation is included in CRM simulation, the ratios obtained from this study would be changed, but not much changed in area mean sense if the area mean includes both of upward and downward branches. To fit the ratio of the GCM to the ratio of the CRM, the cumulus base mass flux was controlled to reduce the intensity of the parameterized convection. The reduction coefficient for the cumulus base mass flux was 0.2 and 0.09 for 100 and $50 \mathrm{~km}$ resolutions, respectively. 

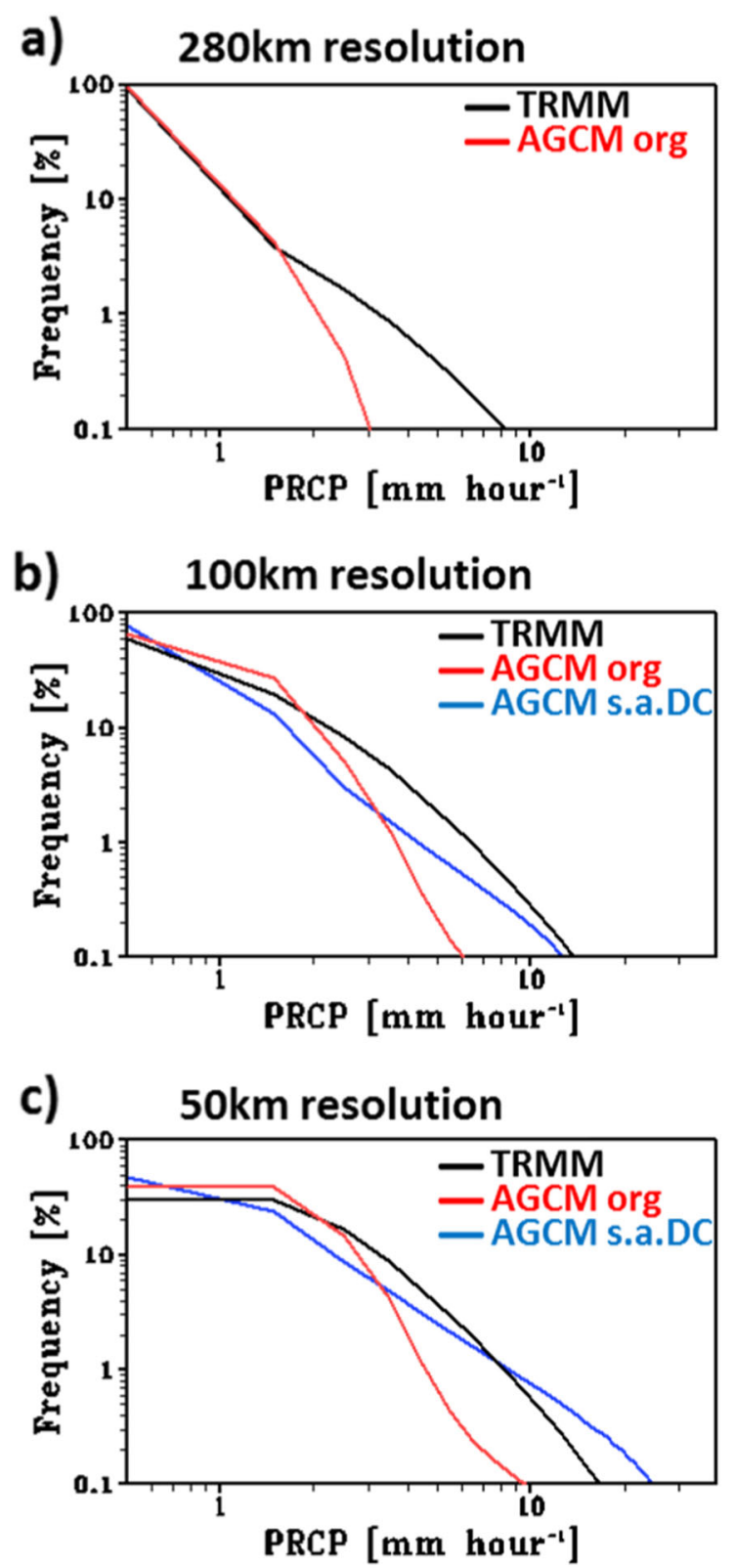

Fig. 5 Frequency distribution of the three-hourly mean precipitation based on the precipitation strength from the TRMM (black curve), original GCM simulation (red curve), and scale-adaptive GCM simulation (blue curve) for the a $280 \mathrm{~km}$ resolution, b $100 \mathrm{~km}$ resolution, and c $50 \mathrm{~km}$ resolution. The domain for $0^{\circ} \mathrm{E}-360^{\circ} \mathrm{E}$ and $30^{\circ} \mathrm{S}-30^{\circ} \mathrm{N}$ was used for the calculation. TRMM data were interpolated to each target grid

The reduction coefficients were obtained through several sensitivity tests because the sub-grid scale vertical transport was not linearly proportional to the reduction coefficient in the timemean sense. The GCM with the scale-adaptive convection showed similar spatial patterns for the mean precipitation, but the variance of the precipitation was increased compared to the original GCM. The precipitation frequency of the three-hourly mean precipitation as a function of the precipitation intensity was well simulated compared to the original GCM. The MJO eastward propagation was improved, but the propagation speed was somewhat faster than that of the observation. This result indicates that the GCM with the more resolved precipitation which are induced by inhibiting the parameterized precipitation improves the precipitation variability although the mean precipitation is not much changed. It may be related to the decrease of the uncertainty contained in the convective parameterization, such as the steady-state assumption which tends to produce too frequent precipitation.

The final goal of the scale-adaptive convection scheme is the appropriate reduction of the sub-grid scale vertical transport as the horizontal resolution increases spontaneously, but this study only presented the appropriate ratio of the sub-grid scale vertical transport to the total vertical transport and applied the ratio to the GCM with 100 and $50 \mathrm{~km}$ horizontal resolution. To achieve the final goal of the scale-adaptive convection by the approach presented in this study, more GCM simulations with higher resolutions than $50 \mathrm{~km}$ resolution are needed to obtain the relationship (or fitting curve) between the reduction coefficient for the cumulus base mass flux and the horizontal resolution. It would be developed in the next study. It is also noted that the inherent change of the parameterized sub-grid scale vertical transport as the horizontal resolution increases would be different depending on the model physics, dynamics, and ocean coupling. Therefore, the ratios of the sub-grid scale vertical transport to the total vertical transport obtained from this study may not completely fit with other GCMs. However, the approach to examine the appropriate sub-grid scale vertical transport presented in this work would be worth to apply to other highresolution GCMs.

\section{METHODS}

The GCM used in this study is the Seoul National University Atmospheric General Circulation Model (SNUAGCM). The model has a finite volume dynamical core $^{25}$ with a hybrid sigma-pressure vertical coordinate. The horizontal resolution of the model is set at 280,100 , and $50 \mathrm{~km}$ with 20 vertical levels. The deep convection scheme is based on the simplified version of the relaxed Arakawa-Schubert convection scheme ${ }^{7}$ with cumulus momentum transports. ${ }^{26}$ The large-scale condensation scheme is based on the diagnostic cloud fraction parameterization. ${ }^{27}$ This scheme converts water vapor exceeding a $\mathrm{RH} 75 \%$ to precipitation with a relaxation time scale of $2400 \mathrm{~s}$. A non-precipitating diffusion-type shallow convection scheme ${ }^{28}$ is also implemented in the model for the midtropospheric moist convection. The boundary layer scheme is a non-local diffusion scheme based on Holtslag and Boville. ${ }^{29}$ Atmospheric radiation processes are parameterized by a two-stream $k$ distribution scheme as in Nakajima. ${ }^{30}$ The land surface processes use the land surface model as in Bonan. ${ }^{31}$ The GCM with different horizontal resolutions (280, 100, and $50 \mathrm{~km}$ ) but with the same parameterization and the same climatologically varying SST prescribed were simulated for 5 years to examine the inherent changes of the GCM as the horizontal resolution was increased. In the $280 \mathrm{~km}$ horizontal resolution, 10-year simulation was conducted and compared with 5-year simulation. The simulation results are not much different. The ratio of the domain averaged $\left(0^{\circ} \mathrm{E}-360^{\circ} \mathrm{E}, 30^{\circ} \mathrm{S}-30^{\circ} \mathrm{N}\right)$ subgrid scale vertical transport to the total vertical transport for the moist static energy at $850 \mathrm{hPa}$ level is about $1.3 \%$ different between the 5 -year simulation and the 10-year simulation. It ensures to some extent that 5year simulation is reasonable for this study. To examine only the influence of the change in the horizontal resolution, the same value for the model time step $(1800 \mathrm{~s})$ was used for the different horizontal resolution simulations because the model time step can induce inherent changes in the GCM.

The CRM used in this study is the Goddard Cumulus Ensemble (GCE) model developed at the National Aeronautic Space Administration/ Goddard Space Flight Center. ${ }^{32,33}$ The governing equation of the GCE model is non-hydrostatic with vertical and horizontal scales appropriate to simulate the convection explicitly. The GCE model allows the gravity wave that triggers clouds and can simulate the growth, mature, and decay processes of clouds. The GCE model is organized by a dynamical core, microphysics, radiation, surface flux, and sub-grid turbulence scheme. The GCE model uses compressible equation ${ }^{34}$ with periodic lateral boundary conditions. Besides basic prognostic variables $\left(u, v, w, \theta, q_{v}\right)$, GCE has prognostic equations for cloud liquid water, cloud ice water, rain, snow, and graupel. Those equations contain advection of species by large-scale motions, and microphysical transfers among hydrometeor species, such as 
a)

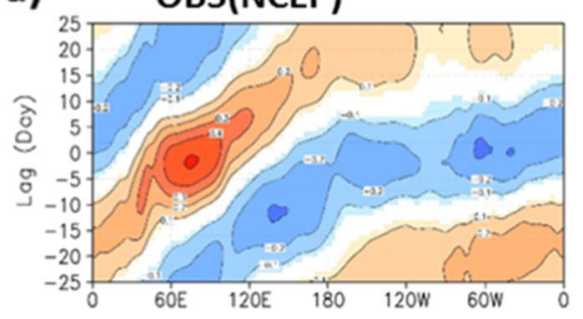

\section{c)}
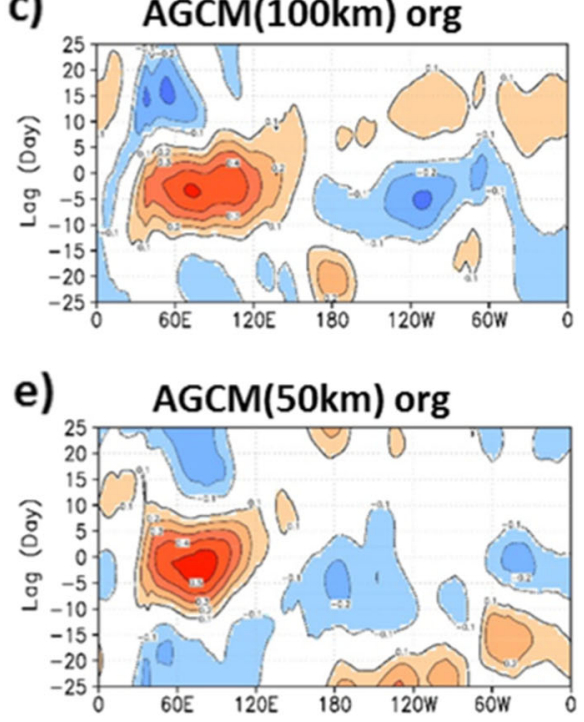

b) $\quad \operatorname{AGCM}(280 \mathrm{~km})$ org

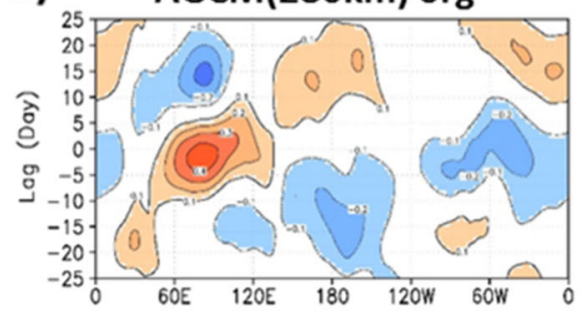

d)

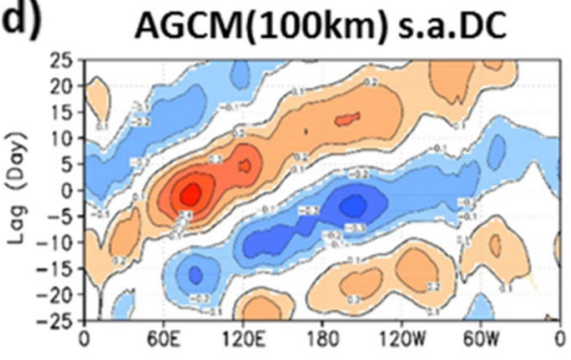

f)

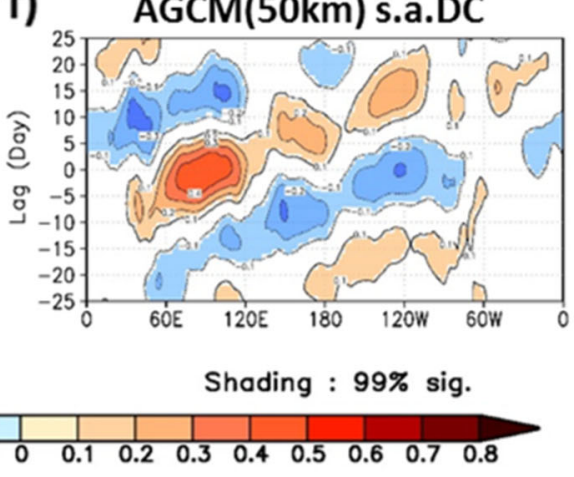

Fig. 6 November-April lag-longitude diagram of the $10^{\circ} \mathrm{S}-10^{\circ} \mathrm{N}$ averaged $850 \mathrm{hPa}$ zonal wind anomaly correlated with $20-100$ day filtered time series at the Indian Ocean averaged base point from the a NCEP, the original GCM simulation with b $280 \mathrm{~km}$, c $100 \mathrm{~km}$, e $50 \mathrm{~km}$ resolutions, and the scale-adaptive GCM simulation with d $100 \mathrm{~km}$ and $\mathbf{f} 50 \mathrm{~km}$ resolutions, respectively. The intervals above $99 \%$ confidence level are shaded

condensation, deposition, accretion, autoconversion, melting, freezing, evaporation, sublimation, etc. The three-dimensional GCE with $1 \mathrm{~km}$ horizontal resolution in $300 \mathrm{~km}^{2}$ domain was simulated to examine the appropriate ratio of the sub-grid scale vertical transport to the total vertical transport as increasing the horizontal resolution. The GCE is designed for the radiative-convective equilibrium (RCE) experiment which is a kind of idealized experiment using the prescribed SST and radiative cooling. This study used the prescribed SST with $302 \mathrm{~K}$ and the radiative cooling with $-1.5 \mathrm{~K} /$ day. These prescribed SST and radiative cooling are favorable conditions for the successive occurrence of the convection. The RCE experiments have been used for the idealization of the mean tropical climate, especially in the mean feature of the tropical convections. ${ }^{35-39}$

The validation data used in this study are the daily mean precipitation for 1998-2011 and the three-hourly mean precipitation for 2000-2004 obtained from the Tropical Rainfall Measuring Mission (TRMM 3B42 version 7), ${ }_{1}^{40}$ and the $850 \mathrm{hPa}$ zonal wind for $1985-2004$ obtained from the NCEP-NCAR reanalysis. ${ }^{41}$

Figures 1 and 4 are obtained from the 5-year time average for the GCM and 14-year time average for the TRMM. Figure 2 is obtained from the time and area average of the $\omega$ and cumulus mass flux vertical profiles in the GCM with scale-adaptive convection. Figure $3 a, b$ is calculated from the time and area average of vertical transport each term of the grid averaged moist static energy equation as a function of the averaged grid size in the three-dimensional CRM with $1 \mathrm{~km}$ horizontal resolution simulation. Figure $3 c$ is calculated from the grid-mean state variables and the tendencies of the temperature and specific humidity parameterized by the deep convection and shallow convection scheme in the GCM with different horizontal resolutions. Figure 5 is calculated by the composite of threehourly precipitation based on the precipitation strength over the tropical domain for the 5-year GCM and 5-year TRMM. Figure 6 is calculated by the lead-lag correlation between the 20 and 100 day filtered Indian Ocean area averaged time series and $10^{\circ} \mathrm{S}-10^{\circ} \mathrm{N}$ averaged variable. The details of this diagnostic are described in MJOWG. ${ }^{42}$

Data availability

The model data used in this study are available from the corresponding author upon request. All observational datasets are obtained from their public websites.

\section{ACKNOWLEDGEMENTS}

The authors would like to thank three anonymous reviewers for their insightful and detailed comments that make much improvements of the manuscript. M.-S.A. was supported by the Korean Meteorological Administration Research and Development Program under grant KMI2018-03214. I.-S.K. was supported by Center of Excellence of Climate Change Research, King Abdulaziz University, Jeddah, Saudi Arabia, and the Brain Korea 21 Plus Program at School of Earth Environmental Sciences, Seoul National University. This work was carried out by utilizing the supercomputer system supported by the National Center for Meteorological Supercomputer of Korea Meteorological Administration (KMA). 


\section{AUTHOR CONTRIBUTIONS}

M.-S.A. and I.-S.K. designed the research, discussed the results, and wrote the paper. M.-S.A. performed the GCM and CRM experiments and conducted analyses.

\section{ADDITIONAL INFORMATION}

Competing interests: The authors declare no competing interests.

Publisher's note: Springer Nature remains neutral with regard to jurisdictional claims in published maps and institutional affiliations.

\section{REFERENCES}

1. Arakawa, A., Jung, J.-H. \& Wu, C.-M. Toward unification of the multiscale modeling of the atmosphere. Atmos. Chem. Phys. 11, 3731-3742 (2011).

2. Hong, S.-Y. \& Dudhia, J. Next-generation numerical weather prediction: bridging parameterization, explicit clouds, and large eddies. Bull. Am. Meteorol. Soc. 93, ES6-ES9 (2012).

3. Arakawa, A. The cumulus parameterization problem: past, present, and future. J. Clim. 17, 2493-2525 (2004).

4. Arakawa, A. \& Schubert, W. H. Interaction of a cumulus cloud ensemble with the large-scale environment, Part I. J. Atmos. Sci. 31, 674-701 (1974).

5. Tiedtke, M. A comprehensive mass flux scheme for cumulus parameterization in large-scale models. Mon. Weather Rev. 117, 1779-1800 (1989).

6. Gregory, D. \& Rowntree, P. A mass flux convection scheme with representation of cloud ensemble characteristics and stability-dependent closure. Mon. Weather Rev. 118, 1483-1506 (1990).

7. Moorthi, S. \& Suarez, M. J. Relaxed Arakawa-Schubert. A parameterization of moist convection for general circulation models. Mon. Weather Rev. 120, 978-1002 (1992).

8. Zhang, G. J. \& McFarlane, N. A. Sensitivity of climate simulations to the parameterization of cumulus convection in the Canadian Climate Centre general circulation model. Atmosphere-Ocean 33, 407-446 (1995).

9. Pan, D. M. \& Randall, D. D. A cumulus parameterization with a prognostic closure. Q. J. R. Meteorol. Soc. 124, 949-981 (1998).

10. Chikira, M. \& Sugiyama, M. A cumulus parameterization with state-dependent entrainment rate. Part I: Description and sensitivity to temperature and humidity profiles.J. Atmos. Sci. 67, 2171-2193 (2010).

11. Kim, D. \& Kang, I.-S. A bulk mass flux convection scheme for climate model: description and moisture sensitivity. Clim. Dyn. 38, 411-429 (2012).

12. Arakawa, A. \& Wu, C.-M. A unified representation of deep moist convection in numerical modeling of the atmosphere. Part I. J. Atmos. Sci. 70, 1977-1992 (2013).

13. Kwon, Y. C. \& Hong, S.-Y. A mass-flux cumulus parameterization scheme across gray-zone resolutions. Mon. Weather Rev. 145, 583-598 (2017).

14. Zhang, G. J., Fan, J. \& Xu, K.-M. Comments on "A unified representation of deep moist convection in numerical modeling of the atmosphere. Part I". J. Atmos. Sci. 72, 2562-2565 (2015).

15. Arakawa, A. \& Wu, C.-M. Reply to "Comments on 'A unified representation of deep moist convection in numerical modeling of the atmosphere. Part I'". J. Atmos. Sci. 72, 2566-2567 (2015).

16. Dai, A. Precipitation characteristics in eighteen coupled climate models. J. Clim. 19, 4605-4630 (2006).

17. Kang, I.-S., Yang, Y.-M. \& Tao, W.-K. GCMs with implicit and explicit representation of cloud microphysics for simulation of extreme precipitation frequency. Clim. Dyn. 45, 325-335 (2015).

18. Slingo, J. et al. Intraseasonal oscillations in 15 atmospheric general circulation models: results from an AMIP diagnostic subproject. Clim. Dyn. 12, 325-357 (1996).

19. Gualdi, S., Navarra, A. \& Von Storch, H. Tropical intraseasonal oscillation appearing in operational analyses and in a family of general circulation models. J. Atmos. Sci. 54, 1185-1202 (1997).

20. Duffy, P. et al. High-resolution simulations of global climate, Part 1: present climate. Clim. Dyn. 21, 371-390 (2003).

21. Jia, X., Li, C., Ling, J. \& Zhang, C. Impacts of a GCM's resolution on MJO simulation. Adv. Atmos. Sci. 25, 139-156 (2008).
22. Tokioka, T., Yamazaki, K., Kitoh, A. \& Ose, T. The equatorial 30-60 day oscillation and the Arakawa-Schubert penetrative cumulus parameterization. J. Meteorol. Soc. Jpn. Ser. II 66, 883-901 (1988).

23. Lee, M.-I., Kang, I.-S. \& Mapes, B. E. Impacts of cumulus convection parameterization on aqua-planet AGCM simulations of tropical intraseasonal variability. J. Meteorol. Soc. Jpn. Ser. I/ 81, 963-992 (2003).

24. Lin, J.-L., Lee, M.-I., Kim, D., Kang, I.-S. \& Frierson, D. M. The impacts of convective parameterization and moisture triggering on AGCM-simulated convectively coupled equatorial waves. J. Clim. 21, 883-909 (2008).

25. Lin, S.-J. A "vertically Lagrangian" finite-volume dynamical core for global models. Mon. Weather Rev. 132, 2293-2307 (2004).

26. Kim, D., Kug, J.-S., Kang, I.-S., Jin, F.-F. \& Wittenberg, A. T. Tropical Pacific impacts of convective momentum transport in the SNU coupled GCM. Clim. Dyn. 31, 213-226 (2008).

27. Le Trent, H. \& Li, Z.-X. Sensitivity of an atmospheric general circulation model to prescribed SST changes: feedback effects associated with the simulation of cloud optical properties. Clim. Dyn. 5, 175-187 (1991).

28. Tiedtke, M. in Workshop on Convection in Large Scale Numerical Models. ECMWF (1985).

29. Holtslag, A. \& Boville, B. Local versus nonlocal boundary-layer diffusion in a global climate model. J. Clim. 6, 1825-1842 (1993).

30. Nakajima, T. Modelling of the radiative process in a AGCM. Climate System Dynamics and Modelling, Reports of A New Program for Creative Basic Research Studies 3, 104-123 (1995).

31. Bonan, G. B. A Land Surface Model (LSM version 1.0) for Ecological, Hydrological, and Atmospheric Studies: Technical Description and User's Guide. NCAR Technical Note NCAR/TN-417+STR (1996).

32. Tao, W.-K. \& Simpson, J. The Goddard cumulus ensemble model. Part I: Model description. Terr. Atmos. Ocean. Sci. 4, 35-72 (1993).

33. Tao, W.-K. et al. Microphysics, radiation and surface processes in the Goddard Cumulus Ensemble (GCE) model. Meteorol. Atmos. Phys. 82, 97-137 (2003).

34. Klemp, J. B. \& Wilhelmson, R. B. The simulation of three-dimensional convective storm dynamics. J. Atmos. Sci. 35, 1070-1096 (1978).

35. Held, I. M., Hemler, R. S. \& Ramaswamy, V. Radiative-convective equilibrium with explicit two-dimensional moist convection. J. Atmos. Sci. 50, 3909-3927 (1993).

36. Tao, W. et al. Equilibrium states simulated by cloud-resolving models. J. Atmos. Sci. 56, 3128-3139 (1999).

37. Bretherton, C. S., Blossey, P. N. \& Khairoutdinov, M. An energy-balance analysis of deep convective self-aggregation above uniform SST. J. Atmos. Sci. 62, 4273-4292 (2005)

38. Muller, C. J. \& Held, I. M. Detailed investigation of the self-aggregation of convection in cloud-resolving simulations. J. Atmos. Sci. 69, 2551-2565 (2012).

39. Khairoutdinov, M. \& Emanuel, K. Rotating radiative-convective equilibrium simulated by a cloud-resolving model. J. Adv. Model. Earth Syst. 5, 816-825 (2013).

40. Huffman, G. J. et al. The TRMM multisatellite precipitation analysis (TMPA): quasiglobal, multiyear, combined-sensor precipitation estimates at fine scales. J. Hydrometeorol. 8, 38-55 (2007).

41. Kalnay, E. et al. The NCEP/NCAR 40-year reanalysis project. Bull. Am. Meteorol. Soc. 77, 437-471 (1996).

42. MJOWG. MJO simulation diagnostics. J. Clim. 22, 3006-3030 (2009).

(c) Open Access This article is licensed under a Creative Commons cc. Attribution 4.0 International License, which permits use, sharing, adaptation, distribution and reproduction in any medium or format, as long as you give appropriate credit to the original author(s) and the source, provide a link to the Creative Commons license, and indicate if changes were made. The images or other third party material in this article are included in the article's Creative Commons license, unless indicated otherwise in a credit line to the material. If material is not included in the article's Creative Commons license and your intended use is not permitted by statutory regulation or exceeds the permitted use, you will need to obtain permission directly from the copyright holder. To view a copy of this license, visit http://creativecommons. org/licenses/by/4.0/.

(c) The Author(s) 2018 